\title{
Quality Management System (ISO 9001) and Environmental Quality Management System (ISO 14001): Towards an integrated model
}

\author{
Raju Roy ${ }^{1}$, Dr. Debomalya Ghose ${ }^{2}$ \\ ${ }^{1}$ Research Scholar, Department of Business Administration, Assam University, Silchar - 788011, Cachar Assam, \\ INDIA \\ ${ }^{2}$ Associate Professor, Department of Business Administration, Assam University, Silchar - 788011 Cachar, \\ Assam, INDIA
}

\begin{abstract}
It is reported by reputed bodies of information that now-a-days integrating management systems are becoming a viable subject. The facilities that integrate the environmental management system (EMS) and quality management system (QMS) can comprehend benefits like decrease in audit costs, streamlined operations, proper decision-making, easy employee training and efficient use of resources. The other management systems like occupation health and safety management (OHSAS 18001) and other organizational activities can be similarly integrated. This is a fact that the drafters of ISO 14001 used ISO 9001:1994 as source document so there are many common elements in the two common models of ISO 9001 (QMS) and ISO I4001 $(E M S)$. Both the standards in their current form are well-suited. To increase the compatibility further, the ISO committees accountable for the improvement and upholding of the aforesaid standards continue to examine possible opportunities.
\end{abstract}

Keywords: Environmental Management System (EMS); Quality Management Systems (QMS); ISO 9001; ISO 14001; Total Quality Management (TQM); Eco Management Auditing Scheme (EMAS); Total Quality Environmental Management Assessment

\section{Quality in business: An introductory overview}

Quality is defined as fitness for purpose and in business; engineering and manufacturing quality has a sensible explanation as superiority of something. The understanding about quality varies from person to person as quality is perceptual, unconfirmed, and somewhat subjective in nature. The consumers mostly measure the quality of a commodity with the available options produced by the competitors in the market. The producers try to quantify quality by assessing degree to which the commodity was produced correctly. The quality measured by support personnel are based on the degree of reliability, maintainability or sustainability of the commodity. In other words, an item that has quality has the ability to perform satisfactorily and is fit for its intended purpose. In business context there are five aspects of quality:

- $\quad$ Producing - providing something

- Checking - confirming that something has been done correctly

- Quality Control - controlling a process to ensure that the outcomes are predictable

- Quality Management - directing an organization so that it optimizes its performance through analysis and improvement

- Quality Assurance - obtaining confidence that a product or service will be satisfactory, normally performed by a purchaser

In many business sectors, quality management has a precise meaning that not only ensures good quality but also make sure that the organization or commodity is consistent. Quality management has four components: quality planning, quality control, quality assurance and quality improvement. ${ }^{1}$

Quality management not only focuses on commodity and its quality, but also shows the way to achieve it. The organizations achieve more consistent quality by using quality assurance and control of processes. The term quality assurance came into existence in 1960s that was used by the procurement directorates of NASA, the military and nuclear industries. The original versions of Quality Management System Standards those were eventually merged to ISO 9001 were designed to contract manufacturers to produce better products, consistently and were focused on Producing, Checking and Quality Control. Later, shift of the quality sector towards management systems can be clearly seen by the aggregation of the product quality requirements into one eighth of the current version of ISO 9001. This augmented emphasis on Quality Management has promoted a general 
perception that quality is about procedures and documentation. The same can be experienced in the areas of Safety Management Systems and Environmental Management Systems. The tools like Asset Optimization and Six Sigma and their emergence is an interesting development in the application of quality principles in business. The fundamentals to any activity is managing quality and survival of an organization and its growth depends on the clear understanding of five aspects, measuring performance and action taken to improve the quality.

\section{Quality Management System (QMS)}

The customer's wants and needs are defined by the quality management system (QMS) that is a collection of business processes focused on achieving quality policy and quality objectives. ${ }^{2}$ One can say that the organizational structure, policies, procedures, processes and resources are needed to implement quality management in an organization. The systems used earlier emphasize expected outcomes of an industrial product production line, using simple statistics and random sampling. In most industrialized societies, by the 20th century, labor inputs were usually the most expensive inputs, so focus shifted to team cooperation and dynamics, particularly the early signaling of problems via a continuous improvement cycle. The Quality Management System (QMS) has tended to converge with sustainability and transparency initiatives in the $21 \mathrm{st}$ century, as both investor and customer satisfaction and perceived quality are increasingly tied to these factors. The most widely implemented family of standards worldwide, among all QMS regimes is ISO 9000. The ISO 19011 audit regime applies to both management systems i.e., ISO 9001 (QMS) and ISO 14001 (EMS), and deals with quality, sustainability and their integration.

\section{Total Quality Management (TQM)}

Generally, the management approach to long-term success through customer satisfaction is known Total Quality Management (TQM). An organization constantly improves its ability to convey high-quality products and services to customers using TQM that set off organization-wide efforts to install and make a permanent climate that leads to quality output. The efforts of TQM were dependent typically on the previouslydeveloped tools and techniques of quality control. During the late 1980s and early 1990s, TQM was a popular management approach that enjoyed extensive consideration, before being overshadowed by ISO 9000, Lean manufacturing, and Six Sigma. In TQM kind of management approach, all members of an organization take part in improving processes, products, services and the culture in which they work. The quality leaders namely Philip B. Crosby, W. Edwards Deming, Armand V. Feigenbaum, Kaoru Ishikawa and Joseph M. Juran taught the world methods of implementing TQM approach. A set of management practices known as Deming's 14 points in implementing TQM, helps companies in increasing their quality and productivity:

- Create constancy of purpose for improving products and services

- $\quad$ Adopt the new philosophy

- Cease dependence on inspection to achieve quality

- End the practice of awarding business on price alone; instead, minimize total cost by working with a single supplier

- Improve constantly and forever every process for planning, production and service

- Institute training on the job

- Adopt and institute leadership

- $\quad$ Drive out fear

- Break down barriers between staff areas

- Eliminate slogans, exhortations and targets for the workforce

- Eliminate numerical quotas for the workforce and numerical goals for management

- Remove barriers that rob people of pride of workmanship, and eliminate the annual rating or merit system

- Institute a vigorous program of education and self-improvement for everyone

- Put everybody in the company to work accomplishing the transformation

The management of total quality is known as TQM. It tries to achieve the quality in fulfilling the needs of the shareholders, the quality of products and services to satisfy or exceed the consumer's needs and the quality of not only the professional but also the personal life of the members of the organization, that's why, the term 'TOTAL' is used. TQM, an approach to the management techniques, started in the 1950's at the Japanese industry development after Second World War. It has become very popular in the West in early 1980's and growing progressively afterward. However, TQM is quality oriented and usually runs separately from the normal management process. TQM is accountability of a quality team considered as simple advisers or staff department. No TQM leadership is extended throughout the organizations in practice, and CEOs (Chief Executive Officers) very frequently tend to rearrange the TQM priorities to more urgent or socially, economically and politically convenient demands. These types of mismanagement don't support the original 
philosophy of TQM and it is need of the time that the fundamentals of TQM are rejuvenated to fight against those malpractices. Moreover, the connection or interaction of process that exists between Globalization and Quality is to be studied meticulously. It is because of the aforesaid reason that many companies have difficulties in implementing TQM. The surveys conducted by Global TQM, An advanced TQM philosophy (www.gtqm.com) have shown that only 20 to $25 \%$ of companies that have implemented TQM systems have registered substantial progress in productivity, competitiveness or financial results.

\section{Popular ISO standards}

The ISO 9001:2015, the revised standard deals with the following:

\section{Clause-4: Context of the Organization}

\subsection{Understanding the organization and its context.}

It is a new requirement that suggests a greater amalgamation between the QMS and wider business planning activities. It requires organisations to make certain, monitor and review both internal and external issues that are relevant to its purpose and strategic direction, and have the ability to impact the QMS and its intended results.

\subsection{Understanding the needs and expectations of interested parties.}

This is sub-clause point to broadening of scope beyond just customers. It requires the organization to determine "the relevant requirements" of "relevant interested parties" e.g. a person or organization that can affect, be affected by, or perceive themselves to be affected by a decision or activity.

\subsection{Determining the scope of the QMS.}

It states that the scope statement must state the products and services covered.

\subsection{The QMS and its processes.}

This is a major change that specifies a number of factors to be considered when planning the processes that make up the QMS. Although a process-planning approach has been previously expressed in earlier standards, this greatly reinforces the requirement.

\section{Clause - 5: Leadership}

5.1 Leadership and commitment.

Greater emphasis is placed on the role of top management. Requires top management to "demonstrate leadership and commitment", and suggests that a more hands-on approach is expected.

\subsection{Quality policy.}

Policy requirements are enhanced. A requirement is introduced that the quality policy is appropriate to the context of the organization, and that it is applied throughout the organization.

\subsection{Organizational roles, responsibilities and authorities.}

The requirement for a Management representative is no longer specified. The duties previously assigned to that role may now be assigned to any role or split across several roles.

\section{Clause - 6: Planning}

6.1 Actions to address risks and opportunities.

A major change introduced to require a risk-based approach. In addition to this clause, reference to the terms 'risk' and 'opportunity' are made throughout the standard.

\subsection{Quality objectives and planning to achieve them.}

Requirements for objective planning are tightened up. An objective should include a description of who is responsible, what is the target, when is it planned to be achieved. Progress must be monitored. Also, requires objectives to be set for relevant processes.

\subsection{Planning of changes.}

The clause lists items to be considered in change management. 


\section{Clause - 7: Support}

\subsection{Resources.}

\subsection{Competence.}

\subsection{Awareness.}

There is an expansion of application from "personnel" to "persons doing work under the organization's control".

\subsection{Communication.}

Now includes external communication about the QMS

\subsection{Documented information.}

New requirement to determine, make available, and maintain knowledge. No requirement for quality manual or procedures. "Documents", "Documentation" and "Records" are combined to become "Documented information". Requirements are expanded to mention issues such as confidentiality, access, and (data) integrity. This suggests an adoption of information security considerations in recognition of the increasing use of electronic documents/data.

\section{Clause - 8: Operations}

In a welcome change of terminology, the rather clumsy 'Product realization' becomes 'Operations'

\subsection{Operational planning and control.}

\subsection{Determination of requirements for products and services.}

\subsection{Design and development of products and services.}

This may be interpreted that more organizations do some form of design and development.

\subsection{Control of externally provided products and services.}

An expansion of scope - from just suppliers to also include other external providers of products and services Purchasing" and "Purchased product" become "Externally provided products and services".

\subsection{Production and service provision.}

An expansion on previous requirements e.g. documented information to specify intended results, and to determine the nature and extent of any post-delivery (after-sales) activities.

\subsection{Release of products and services.}

\subsection{Control of nonconforming process outputs, products and services.}

\section{Clause - 9: Performance Evaluation}

9.1 Monitoring, measurement, analysis and evaluation.

There is a new requirement to obtain information relating to customer views and opinions of the organization.

\subsection{Internal audit.}

Audit schedule must take customer feedback into account.

\subsection{Management review.}

Expanded requirements for management review inputs or agenda.

Clause - 10: Improvement

10.1 General.

10.2 Nonconformity and corrective action. 
Specific reference to preventive action is removed. Now includes an additional requirement to record the nature of nonconformities. On discovering nonconformity, an explicit requirement is introduced for organisations to determine whether other similar nonconformities actually exist, or could potentially exist.

\subsection{Continual improvement.}

There are some more popular standards and they are as follows:

- ISO 9000 Quality management

- ISO 14000 Environmental management

- ISO 3166 Country codes

- ISO 26000 Social responsibility

- ISO 50001 Energy management

- ISO 31000 Risk management

- ISO 22000 Food safety management

- ISO 27001 Information security management

- ISO 20121 Sustainable events

Normally, the companies look for two popular certificates and they are - ISO 9000 family and ISO 14000. ISO 9000 is related to quality management that addresses customer requirements, customer satisfaction and adherence to regulations and strive of continuous improvement. ISO 14000 is linked to the impact of the firm's activities on the environment and the firm's attempts to improve its performance in this respect.

\section{Development of the ISO 14000 Series}

It is well-known that Environmental Management Standards (EMS) i.e. ISO 14000 facilitates in (i) It reduces the negative effect on the environment created due to operational deficiency. (ii) It makes facilities to comply with applicable laws, regulations, and other environmentally oriented requirements, and (iii) It convey continuous improvement in the above facilities. The standards i.e. ISO 14000 and ISO 9000, both are concerned about the process of production of product rather than the product itself and that's why both are similar in nature. As ISO don't certify any organization directly, certification of ISO 9000 and ISO 14000 is performed by thirdparty organizations or certification bodies. When auditing for both 9000 and 14000 standard and their compliances, the auditors apply ISO 19011 audit standard that is applicable on both the management systems.

\section{ISO 14001 Standard}

ISO 14001 Standard does not articulate completely about environmental performance requirements as it is not an environmental management system (National Academy Press 1999), but it provide an outline to the companies and assist them in development of their own environmental management system (RMIT University). The management system ISO 14001 assists companies in meeting their environmental and economic goals and can be incorporated with other management functions. In comparison to other ISO 14000 standards, ISO 14001 is voluntary (IISD 2010), and its main aim is to assist companies in continuous improvement of their environmental performance and at the same time complying with any applicable legislation. Basically, the organizations are liable for setting their own targets and performance measures. ISO standards assist them in meeting objectives and goals and help the management in proper monitoring and measurement of internal activities and operations (IISD 2010). In other words, any two organizations with completely different measures and standards of environmental performance, can comply with ISO 14001 requirements (Federal Facilities Council Report 1999).

The standard is applicable at different levels of business i.e. organizational, product and service level. The standard highlights the organizational needs and provides necessary guidelines to meet the goals of environmental performance, rather than focusing on exact measures and goals (IISD 2010). The involvement and commitment at all levels of organization, especially top management, makes the standard and system successful (Standards Australia/Standards New Zealand 2004). The active involvement of the top management and other levels of organization help in development, implementation and maintenance of the environmental management system (ISO14001.com.au 2010). In the year 2008, nearly 188000 companies from 155 countries in the world were found ISO 14001 certified (ISO14001.com.au 2010). The standard is generic management system standard that means it is applicable to any size and type of organization, product or service, in any sector of activity and can accommodate varied socio-cultural and geographic conditions (Standards Australia/Standards New Zealand 2004). The ISO standards are periodically reviewed by ISO and new ones are issued time-to-time (Standards Australia/Standards New Zealand 2004). 


\section{Environmental Management Systems: A historical perspective}

The environmental management system came to existence in the early nineties, but was initiated in 1972, when the United Nations organized a Conference on the Human Environment in Stockholm and the United Nations Environment Programme (UNEP) was launched (Corbett \& Kirsch, 2001). The framing of World Commission on Environment and Development (WCED) and the adoption of the Montreal Protocol and Basel Convention was due to the early initiatives taken in the year 1972. In 1992, the first Earth Summit which served to generate a global commitment to the environment was held in Rio-de-Janeiro (Jiang \& Bansal, 2001). The world's first environmental management systems standard, BS 7750 was published by BSI Group in the same year. This template was the preliminary guidelines for International Organization for Standardization, which has representation from committees all over the world (ISO) that developed the standard ISO 14000 series in 1996 (Clements 1996, Brorson \& Larsson, 1999). The remarkable ISO 14001 standard is included in the ISO 14000 family, which represents the core set of standards used by organizations for designing and implementing an effective environmental management system. The standard other than ISO 14001 is ISO 14004 that gives additional guidelines for a good environmental management system, and more specialized standards deal with specific aspects of environmental management. The effective and efficient promotion of environmental management in an organization and to facilitate useful and usable tools those are cost effective, system-based, flexible and reflect the best organizations and the best organizational practices available for gathering, interpreting and communicating environmentally relevant information is the main objective of the ISO 14000 series of norms.

Previous environmental regulations were with full of command and control approaches and were replaced with ones based on market mechanisms, whereas ISO 14000 was designed on the basis of voluntary approach to environmental regulation (Szymanski \& Tiwari 2004). The ISO 14000 series comprises the ISO 14001 standard that gives guidelines for the establishment or improvement of an EMS. There are many common traits in the standard that is similar to its predecessor ISO 9000, the international standard of quality management (Jackson 1997) that provides a model for its inner structure (National Academy Press 1999) and both can be implemented at a time. One can say that ISO 9000 and ISO 14000 not only act as an internal management tool but also represent the company's environmental obligation to its customers and clients (Boiral 2007). Before development of ISO 14000 series, most of the organizations willingly framed their own EMS systems and due to which the assessment of environmental effects between companies became difficult and as a result the universal ISO 14000 series came into existence. ISO defined EMS as a part the overall management system and it comprises organizational structure, planning activities, responsibilities, practices, procedures, processes and resources for developing, implementing, achieving and maintaining the environmental policy (ISO 1996 cited in Federal Facilities Council Report 1999). International organization for standardization, in the year 1996, approved ISO 14001 which presents a set of requirement pertaining to the company's external environment (Larsen and Häversjö 1999). After updating and necessary revision the present standard ISO 14001:2004 is at hand that is a specification standard and descriptive document.

\section{Basic Principles and Methodologies of ISO 14001}

The overall goal and fundamental principle of the ISO 14001 standard is continual improvement (Federal Facilities Council Report 1999). The basis if ISO 14001 is Plan-Do-Check-Act methodology (Standards Australia/Standards New Zealand 2004) that comprises 17 elements and it is grouped into five phases that relates Plan-Do-Check-Act; Environmental Policy, Planning, Implementation \& Operation, Checking \& Corrective Action and lastly Management Review (Martin 1998).

The implementation of ISO 14001 always recommend an initial review or gap analysis of the organization's processes and products to assist in recognizing all elements of the current operation and if possible future operations, that may interact with the environment, termed environmental aspects (Martin 1998). The environmental aspects are of two types i.e., direct aspects- those used during manufacturing and indirect aspects- such as raw materials (Martin 1998). The organization's get benefit of this review in establishing their environmental objectives, goals and targets, which should ideally be measurable; helps with the development of control and management procedures and processes and serves to highlight any relevant legal requirements, which can then be built into the policy (Standards Australia/Standards New Zealand 2004).

When an organization wishes to improve its environmental performance by controlling the impact of its activities, services and products on environment and it wants to be consistent with environmental laws and policies in that case, ISO 14001 provides a structured management system to the organization. The basis of this standard is Plan-Do-Check-Act (PDCA) model proposed by Deming and it is applicable to all processes in a company so it can be easily observed that there is a prominent link and compatibility between ISO 9001 and 14001. There are four iterative steps in PDCA (plan-do-check-act or plan-do-check-adjust) management method used in business for the control and continuous improvement of processes and products. ${ }^{3}$ PDCA is also known as the Deming circle/cycle/wheel, Shewhart cycle, control circle/cycle, or plan-do-study-act (PDSA). 
Quality Management System (ISO 9001) and Environmental Quality Management System (ISO...

The other version of PDCA cycle is OPDCA. Here "O" stands for observation or as some versions say "Grasp the current condition." This stress on observation and current condition has concurrence with Lean manufacturing/Toyota Production System literature. ${ }^{4}$

- $\quad$ PLAN: It means establishment of objectives and processes required to bring results in accordance with the expected output. The absoluteness and accurateness of the specification is also a part of the targeted improvement that can be achieved once output expectations are established. It is the possibility to start on a small scale to test possible effects.

- DO: It is the way to implement the plan, carry out the procedure and make the product. It helps in collecting data for preparation of charts and analysis the "CHECK" and "ACT" steps.

- CHECK: It study the actual results measured and collected in "DO" and compare it against the expected results, targets or goals from the "PLAN" to determine differences. On the way to enable the implementation "DO", one must look for deviation in implementation from the plan and also look for the appropriateness and completeness of the plan. The charting data can make this simple to see tendency over several PDCA cycles and in order to translate the collected data into information. The information is what one needs for the next step "ACT".

- ACT: These are the request corrective actions on significant differences between actual and planned results to analyze the differences to determine their root causes and to determine where to apply changes that will include improvement of the process or product. If passing through aforesaid four steps doesn't give any indication towards need to improve, the scope to which PDCA is applied may be improved to plan and get better with more detail in the next iteration of the cycle, or attention needs to be placed in a different stage of the process.

Instead of thinking that the "A" is all about action and implementation, now a day, contemporary guides refer to "A" as "Adjust" that assists trainees to know that the 4th step is more about adjusting/correcting the difference between the current state and the planned state. Dr. W. Edwards Deming made PDCA popular and he is considered to be the father of modern quality control; however, he always referred to it as the "Shewhart cycle". Dr. W. Edwards Deming later modified PDCA to "Plan, Do, Study, Act" (PDSA) as he thought and considered that "check" stressed inspection over analysis. As developed from the effort of Francis Bacon (Novum Organum, 1620), the perception of PDCA is based on the scientific method. ${ }^{5}$ The scientific method can be written as "hypothesis"-"experiment"-"evaluation" or plan, do and check. As per Shewhart, manufacturing under statistical "control" is a three-step process of specification, production, and inspection. He further related this to the scientific method of hypothesis, experiment, and evaluation. It was further asserted by Shewhart that the statistician needs to help to change the demand for goods by demonstrating the close up of the tolerance range and by developing the quality of goods. Shewhart clearly proposed the analyst to take action based on the conclusions of the evaluation. The available records point out that during the lectures of Deming in Japan in the early 1950s, the Japanese participants reduced the steps to the present traditional plan, do, check, act. Actually, Deming preferred plan, do, study, act because "study" has association in English closer to Shewhart's intent than "check". ${ }^{6}$ The iteration is the fundamental principle of the scientific method and PDCAexecuting the cycle again will extend the knowledge further, once a hypothesis is established or negated. Repetition of the PDCA cycle can bring us closer to the goal, usually a perfect operation and output. There is another basic purpose of PDCA and that is the "hygienic" separation of its each phase. If it is not properly separated, measurements of effects due to various simultaneous actions will raise the risk of becoming confounded. ${ }^{7}$ PDCA and other forms of scientific problem solving is also known as a methods for developing critical thinking. At Toyota this is known as "Building people before building cars. ${ }^{8}$ As per proposal of Toyota and other Lean companies, an engaged, problem-solving workforce using PDCA is superior in innovation and stay ahead of the competition through careful problem solving and the successive innovations. This initiates and creates a culture of problem solvers using PDCA and constructing a culture of critical thinkers. In Six Sigma programs, the PDCA cycle is called "define, measure, analyze, improve, control" (DMAIC). One must keep in mind that the iterative nature of the PDCA cycle must be added to DMAIC procedure.

Deming continually advocated in putting emphasis on iterating towards an improved system so that PDCA should be repeatedly implemented in spirals of increasing knowledge of the system that converge on the ultimate goal. Here each cycle is closer than the previous one. The process is similar to the structure of an open coil spring, with each loop being one cycle of the scientific method - PDCA, and each complete cycle representing an increase in our knowledge of the system under study. This is a fact that our knowledge and skills are limited, but improving and this approach supports that belief. Key information may not be known at the start of a project; the PDCA — scientific method-provides feedback to justify our guesses (hypotheses) and increase our knowledge. Instead of facing "analysis paralysis" in search of perfection at first attempt, it is better to be approximately right than exactly wrong. One can choose to refine or alter the goal with the improved knowledge 
(ideal state). It can be said that the PDCA approach can bring us closer to whatever goal we choose. Here rate of change or rate of improvement can be considered as key competitive factor in today's world. PDCA not only permits major "jumps" in performance i.e. "breakthroughs" time and again as preferred in a Western approach but also allows Kaizen or frequent small improvements. A PDCA approach in the United States is generally associated with a sizeable or massive project that involves several people's time, and thus managers want to see large "breakthrough" improvements to justify the effort expended. Usually, the scientific method and PDCA is relevant to all sorts of projects and development activities.

\section{Eco Management Auditing Scheme (EMAS)}

In 1993, the European Commission framed a fixed system on the environmental management and audit for use in production companies called EMAS, later turned into voluntary after protest from companies. (Jorgensen, 2001) EMAS registered organizations are operational mostly in Europe.

\section{Continual Improvement Process}

The quality management system is different from the core requirement of a continual improvement process (CIP). There are three dimensions of CIP in ISO 14001 (Gastl, 2):

- Expansion: By implementing EMS, more and more business areas get covered.

- Enrichment: Implementation of EMS enables to manage more and more activities, products, processes, emissions, resources etc.

- Upgrading: It is the improvement of the structural and organizational framework of the EMS and accumulation of know-how in dealing with business related environmental issues.

In general, gradually moving away of companies from merely operational environmental measures towards a strategic approach on how to deal with environmental challenges is what the continual improvement process (CIP)-concept expects.

\section{Benefits}

To assist the organizations in reducing environmental impact, ISO 14001 was developed. By utilizing the ISO standard along with improvement in environmental standards and performance, organizations are also getting economic benefits viz., higher conformance with legislative and regulatory requirements (Sheldon 1997). Firstly by reducing the threat of regulatory and environmental liability fines and improving an organization's competence (Delmas 2001), leading to a decrease in waste and use of resources, and reduced operating cost (ISO14001.com.au 2010). Secondly due to its international status, the businesses operating in various locations across the globe can register as ISO 14001 compliant, eradicating the need for multiple registrations or certifications (Hutchens 2010). Thirdly, the consumers world-wide are aware of the management systems and there is a push in the last decade from their end for companies to adopt stricter environmental regulations, making the amalgamation of ISO 14001 a larger necessity for the long term viability of businesses (Delmas \& Montiel 2009) and providing them with a competitive advantage against companies that do not adopt the standard (Potoki \& Prakash, 2005). The implementation of ISO 14001 in a company gives a positive impact on the company's asset value (Van der Deldt, 1997) and can lead to better public perceptions of the business, placing them in a better position to operate in the international market (Potoki \& Prakash 1997; Sheldon 1997). Finally it is reducing the trade barriers between registered businesses (Van der Deldt, 1997).

The EMS implementation in organizations can considerably benefit through the identification of large cleaner production projects, for example, considerable cut in electricity costs in manufacturing industries. A very effective tool like ISO 14001 can identify cost savings opportunities for businesses. The organizations with less planning, lack of senior management commitment and poor understanding of ISO 14001 are unable to implement an effective EMS system. They need to improve their planning, allocate adequate resources, provide training and create forums for discussion, set measurable targets and work according to the philosophy of continuous improvement (Burden, 2010).

The management system ISO 14001 is very helpful and can be used fully or in part, for a profit making or a not-for-profit organization and it also manages the relationship of organization with its environment. The organization may choose to establish that it has attained full alignment or conformity with the international standard, ISO 14001, if all the fundamentals of ISO 14001 are included into the management process. One can use one of four documented alternatives, those are as follows:

- to make a self-determination and self-declaration, or

- to ask for authentication of its conformance by parties having an importance in the organization, such as customers, or

- to look for authentication of its self-declaration by a party external to the organization, or 
- $\quad$ try to find out certification/registration of its environmental management system by an external body.

(Source: ISO 14001: 2004, Clause 1: Scope c)

There are few options of ISO 14001 management system audits and they are not comparable and serve differently as per different market needs. It depends on the organizations to choose the best options that suits their market needs.

The first option, self-certify or self-certification is incorrect and not an acceptable reference under ISO terms and definitions, for it can lead to confusion in the market. ${ }^{9}$

The second option is known as a customer or 2nd party audit and it is an acceptable market term.

The third option is an independent third-party process that is based on the EnviroReady Report that is the proprietary name for a service given by specially trained proficient auditors. The training process for auditors is managed by 14000registry.com. It is classified by ISO as a recognition scheme. It was proposed to assist small and medium-sized enterprise, but can be used by any entity.

The fourth option is known as certification and it is another independent third-party process. It is mostly used by large firms. In some markets certification is also known as registration. Service providers of certification or registration are accredited by national standards bodies and are recorded on the website of the national standards body.

\section{ISO 14001 Consultancy}

ISO 14001 is a management system standard that speaks about environmental issues and help organizations to identify and assess environmental aspects and take essential control to reduce environmental impacts. Some organizations consider handling ISO 14001 a chaotic job and they employ ISO 14001 consultancy firms to solve the technical environmental issues. While implementing ISO 14001 the organizations arrange training for their employees that is considered first step and later think about ISO 14001 consultancies.

\section{ISO 14001 Software}

There are many ISO 14001 software that helps organizations in managing their environmental operation.

\section{ISO 14001 Environmental Aspect Database}

The identification and assessment are the most important environmental aspects and impacts for implementation of ISO 14001. Most of the organizations or companies prepare a list of environmental aspects and impacts and utilize it to perform environmental controls and write down the environmental procedures. The environmental aspects and impacts are usually communicated to the staff of the organization to create environmental awareness. The companies try to make the search of environmental aspects easy for the staff by using environmental aspect database instead of long lists, as it can be searched more easily to find related environmental issues.

\section{List of ISO 14000 Series Standards}

- ISO 14001 Environmental management systems - Requirements with guidance for use

- ISO 14004 Environmental management systems - General guidelines on principles, systems and support techniques

- ISO 14015 Environmental assessment of sites and organizations

- ISO 14020 series (14020 to 14025) Environmental labels and declarations

- ISO 14030 discusses post production environmental assessment

- ISO 14031 Environmental performance evaluation- Guidelines

- ISO 14040 series (14040 to 14049), Life Cycle Assessment, LCA, discusses pre- production planning and environment goal setting.

- ISO 14050 terms and definitions.

- ISO 14062 discusses making improvements to environmental impact goals.

- ISO 14063 Environmental communication-Guidelines and examples

- ISO 14064 Measuring, quantifying, and reducing Greenhouse Gas emissions.

ISO 19011 is known as one audit protocol for both ISO 14000 and ISO 9000 series standards jointly and it replaced the ISO 14011 meta-evaluation. Presently, ISO 19011 is the only recommended way to conduct joint audit for both ISO 14000 and ISO 9000 series standards. 


\section{Integration Based On ISO 14001}

The environmental management systems, as mentioned in ISO 14001, focuses fully on environmental aspects that means it needs the elements like policy, planning, implementation, operations, checking, corrective action and management review to get the desired result. The model is represented below:

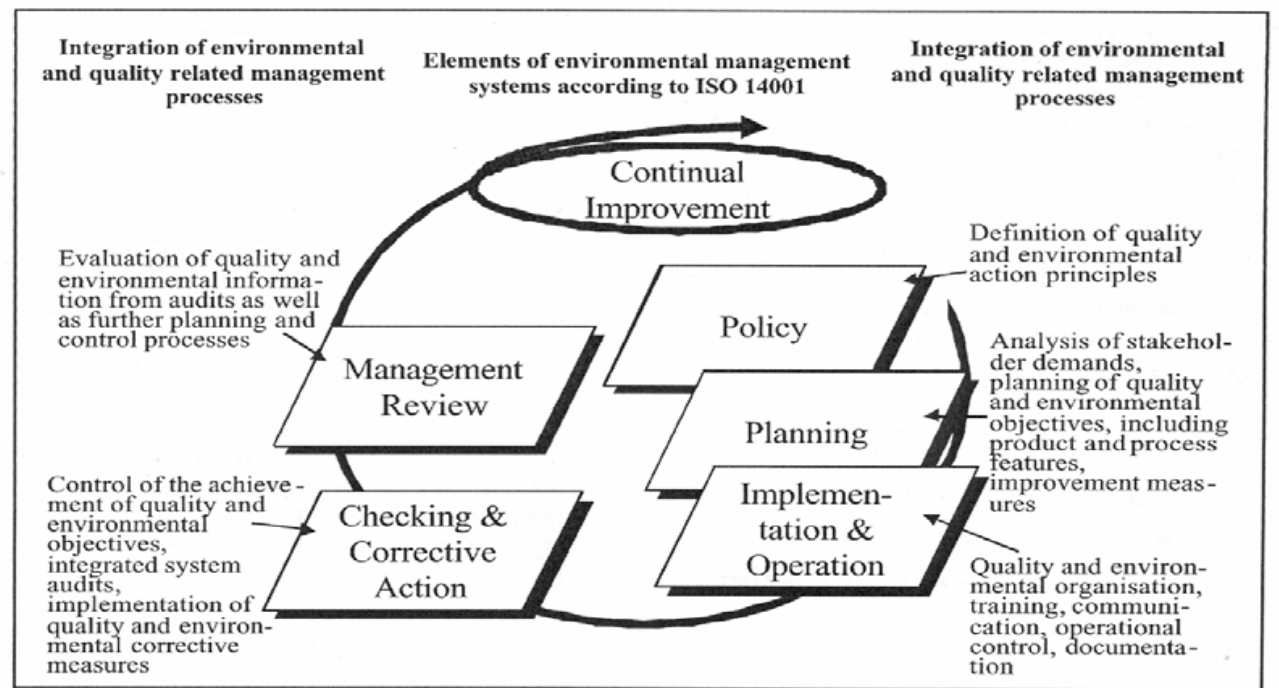

Figure 1.

Source: An integration model based on the underlying model of ISO 14001 (Integration of ISO 9001 and ISO 14001) (Ahsen and Funck 2001).

The requirements of this model are environment, quality, health, safety and other required systems and they need to be well thought-out in all processes and should be documented in all operation, processes and guidelines. An important study was carried out by Ahsen and Funck (2001) in Germany which suggests that the integration model is feasible and effective.

\section{Total Quality Environmental Management (TQEM)}

Total Quality Environmental Management means the business management practices that decrease or prevent environmental pollution attained through Total Quality Management techniques (Albero A, 1999). In and around 1995, the literature related to this topic subsides with the increase in acceptance of ISO 14001.

\section{Socio-Industrial Facets of Total Quality Environmental Management}

The environmental pollution cannot be controlled or checked by dedicated effort of an individual only. It can't be a one man show. To raise the environmental standards, it requires involvement of all levels of organization and the society. Accordingly, through industry teamwork and in collaboration with regulators, businesses can collectively accomplish environmental improvements, thereby creating an alternative to strict regulatory control. Total Quality Environmental Management is also known as an Alliance Framework. ${ }^{10}$ It is a fact that during execution, most of the companies find it difficult to place over another company's quality system $^{11}$ on their own. It is like pouring beer into a soda pop container that can't change the beer's taste into cola. ${ }^{12}$ Therefore, we can say that Total Quality Environmental Management implementations deals with the exceptional features of each operating facility. The performance indicators for Total Quality Environmental Management in the year 1992 were in the early stages of development (Johansson, 1992) though a very less work in the area has taken place since. ${ }^{13}$

\section{Total Quality Environmental Management Measures}

The identification of the costs of environmental projects based on Juran's COQ approach is just an early conceptual framework and the empirical examination of the proposed framework is still untested. ${ }^{14}$ The Total Quality Environmental Management cost is not covered under Total Quality Management frameworks and frameworks of capturing environment. The measurements in the test of two TQEM measures with good $\chi^{2}$ hold limited practical usefulness as per Del Brio et al. (2000). The study of Del Brio et al. on managers of Spanish industrial companies, ascertain some communication between their attitude towards the environment based on their perception of the advantages and difficulties of environmental actions. The study established a communication between the importance that managers attach to the adoption of a series of tools and the formal consideration they give to the environmental area; the managers were more concerned about the environmental advantages, difficulties and tools working in companies that attach more formal importance to the 
Quality Management System (ISO 9001) and Environmental Quality Management System (ISO...

environmental area. The study also initiated some correspondence between obtaining an environmental management certificate and the formal consideration given to the environmental area by managers. The companies with an environmental management certificate reflect more formal importance to the environmental area. ${ }^{15}$ The four factors based on literature related to Green supply chain practices were defined as: internal environment management, external GSCM practices, inventory recovery, and eco-design. In broader sense, QM revolves around two main activities and they are TQM and ISO 9000 certification. (Zhu \& Sarkis, 2004)

\section{Recent Total Quality Environmental Management Assessment}

A recent examination of Total Quality Environmental Management after successful introduction of ISO 14001 was presented by Jayathirtha $(2001)^{\mathbf{1 6}}$. There are some common requirements in both ISO 9000 and ISO 14000 series standards:

- Doing business as usual is "unacceptable."

- Doing business without a systematic management approach is economic doom.

- Providing quality is key.

- Protecting and nurturing the environment is the key.

- Doing it right the first time is crucial.

- Getting your act together is essential.

- Listening to customers and other stakeholders is absolutely necessary.

- Respecting society is mandatory.

The objectives of Total Quality Environmental Management are to:

- reduce waste and improve continuously,

- reduce resource depletion,

- reduce or eliminate environmental pollution,

- design products for minimal environmental impact in production, use and disposal,

- control environmental impact of raw material sourcing,

- control environmental impact of new developments,

- $\quad$ promote environmental awareness among employees, and

- promote environmental awareness within the community.

\section{Conclusion and recommendations}

It is clear from the analysis that the ISO 9001 (QMS) and ISO 14001 (EMS) International Standards share much in common and in that way, justify the integrated approach. The companies that have an existing ISO 9001 and wish to integrate an ISO 14001 with it may require understanding the following:

- The companies must understand the existing QMS and its effectiveness, perception of the workforce regarding the system and clarity and workability of the existing QMS documentation. In other words, the members of staff must believe that the system is helping the facility to achieve desired result.

- The companies must ensure that the scope of the two systems is consistent i.e., the systems will cover the same facilities, products, activities, and/or services. In particular, this will be an important issue if thirdparty registration will be sought.

- To determine the optimal approach to system integration, the companies must establish a Cross Functional Team (including, at a minimum, representatives from the environmental and quality functions).

- It is a fact that some employees and managers may be reluctant to change a system with which they are already familiar and/or in which they have important roles. In that case, the company has to manage resistance to change as needed.

- The companies must understand the difference of purpose between QMS and EMS. If there are many common management system elements, there are elements of each system that are unique too. In the case of EMS, these include, for example, environmental aspects, communications, and emergency preparedness and response. These differences must be acknowledged and accommodated within the integrated management system.

- The companies have to modify system documentation as required and keep procedures simple and clear for users. Moreover, review of proposed changes on affected managers and employees must be observed and be given due importance.

- The companies have to consider whether to integrate the procedures or keep them separate on a procedureby-procedure basis. If integration can reduce the total number of procedures or work instructions, it also can confuse the overall purpose of such procedures, in some cases. 
- Proper training must be imparted to managers and employees on the integrated system once the integrated system documentation has been prepared.

- The companies must arrange internal and surveillance audits of the integrated system and take actions as necessary.

\section{References}

[1] Rose, Kenneth H. (July 2005). Project Quality Management: Why, What and How. Fort Lauderdale, Florida: J. Ross Publishing. p. 41. ISBN 1-932159-48-7.

[2] Anderson, Chris. What is a Quality Management System? Bizmanualz, Nov 18, 2013.

[3] Deming, W. Edwards (1986). Out of the Crisis. MIT Center for Advanced Engineering Study. ISBN 0-911379-01-0.

[4] Rother, Mike (2010). "6". Toyota Kata. New York: MGraw-Hill. ISBN 978-0-07-163523-3.

[5] Anderson, Chris. How Are PDCA Cycles Used?, Bizmanualz, June 7, 2011.

[6] Shewhart, Walter Andrew (1980). Economic Control of Quality of Manufactured Product/50th Anniversary Commemorative Issue. American Society for Quality. ISBN 0-87389-076-0.

[7] Berengueres, Jose (2007). The toyota production system re-contextualized. Tokyo. p. 74. ISBN 1847534775.

[8] Liker, Jeffrey (2004). "1". The Toyota Way. McGraw-Hill. ISBN 0-07-139231-9.

[9] ISO/ IEC 17000:2004(E/F/R).

[10] O'Dea, K. and Pratt, K. (1995). Achieving Environmental Excellence through TQEM Strategic Alliances. Total Quality Environmental Management Spring (1995): 93-108.

[11] Ibid.9

[12] Woods, S. (1993). Making Pollution Prevention Part of the Coors Culture. Total Quality Environmental Management Autumn (1993): 31-38.

[13] Johannson, L. (1992a). TQEM Performance Indicators - How do you Measure Up? Total Quality Environmental Management Summer (1992): 415-419.

[14] Curkovic, S.; Sroufe, R. and Landeros, R. (2005). Measuring TQEM Returns from the Application of Quality Frameworks. Business Strategy and the Environment 17 (1): 93-106.]

[15] del Brío, C.J. (2000). Environmental managers and departments as driving forces of TQEM in Spanish industrial companies. International Journal of Quality and Reliability Management 18(5): 495-511.

[16] Jayathirtha, R. V. (2001). Combating Environmental Repercussions through 'TQEM' and 'ISO 14000'. Business Strategy and the Environment 10: 245-250. 